\title{
Há em Foucault um gesto inaugural nos estudos do discurso?
}

\author{
Is Foucault an inaugural gesture in discourse studies?
}

\author{
Vanice Maria Oliveira Sargentini ${ }^{1}$ \\ Universidade Federal de São Carlos - UFSCar
}

\begin{abstract}
RESUMO: Os estudos do discurso iniciados na França nos anos de 1960 foram reverberados nos anos seguintes em várias disciplinas e estenderam-se a outros países europeus e a outros continentes. Este artigo procura recuperar o contexto de aparição de conceitos basilares para os estudos do discurso, investigando como as reflexões teórico-analíticas de Michel Foucault nos livros Arqueologia do Saber e A Ordem do discurso e em seus comentadores são responsáveis por um gesto inaugural disciplinar que se estabeleceu com as noções de discurso, formação discursiva, arquivo, descontinuidades, sistemas. Avalia-se, portanto, como a Arqueologia foi central para revolucionar a História, para questionar o poder do arquivo, para dar centralidade ao discurso. Considerando o alcance dos conceitos discutidos em M. Foucault, avalia-se ainda a produtividade de discussões que se seguiram às reflexões sobre a arqueologia, na segunda metade dos anos de 1970, envolvendo as noções de saber-poder, poder disciplinar e biopoder. Pretende-se com isso, validar o gesto inaugural de Foucault para os estudos do discurso e expor os cortes epistemológicos, os deslocamentos científicos e o pensamento inovador que vieram a constituir esse campo disciplinar que continua a ser produtivo para análise dos discursos da atualidade.
\end{abstract}

Palavras-chave: Arqueologia; Genealogia; Michel Foucault; Discurso.

ABSTRACT: The discourse studies begun in France in the 1960s were reverberated in the following years in various disciplines and extended to other European countries and to other continents. This article intends to recover the context of appearance of basic concepts for the studies of the discourse, investigating how Michel Foucault's theoretical-analytical reflections in the books A Arqueologia do Saber and A Ordem do Discurso and in their commentators are responsible for an inaugural disciplinary gesture that established with the notions of discourse, discursive formation, archive, discontinuities, systems. It is therefore evaluated how Archeology was central to revolutionizing History, to question the power of the archive, to give centrality to the discourse. Considering the scope of the concepts discussed in M. Foucault, we also evaluate the productivity of discussions that followed the reflections on archeology in the second half of the 1970s, involving the notions of know-power, disciplinary power and biopower. The aim is to validate Foucault's inaugural gesture for discourse studies and to expose the epistemological cuts, scientific displacements and innovative thinking that came to constitute this disciplinary field that continues to be productive for the analysis of current discourses.

Keywords: Archeology; Genealogy; Michel Foucault; Discourse.

\footnotetext{
${ }^{1}$ Professora Doutora do Programa de Pós-Graduação em Linguística da Universidade Federal de São Carlos (PPGL/UFSCar). Líder do Laboratório de Estudos Discursivos (LABOR).
} 


\section{Introdução}

A publicação de A arqueologia do Saber completa, neste ano de 2019, 50 anos e a atualidade desse texto é objeto de discussão em diferentes disciplinas e por inúmeros autores. L'archéologie du savoir, publicada pelas Éditions Gallimard, em 1969, é uma publicação que atrai amores e furores que, na ausência da noção de episteme, afasta-se do estruturalismo sem vincular sua proposta do método arqueológico às teses humanistas. Uma operação delicada que leva Foucault ao embate com os admiradores de seus trabalhos anteriores que desenvolvera com as estruturas epistêmicas, e à aliança com aqueles que souberam reconhecer o modo como a Arqueologia foi central para revolucionar a História, para questionar o poder do arquivo, para dar centralidade ao discurso.

O ponto de articulação das proposições de M. Foucault com os estudos do discurso construiu-se particularmente em A arqueologia do Saber e em A ordem do discurso. Ainda que em As palavras e as Coisas já se exibisse o diálogo conflituoso com a Linguística, foi na descrição do método arqueológico que Foucault problematizou e elaborou a noção de discurso, de práticas discursivas, de arquivo, vinculando-se, neste caso, às reflexões dos estudiosos da Nova História, que questionaram a forma de composição do arquivo, em geral pautado em longos períodos, em continuidades seculares. M. Foucault propõe que se questionem os estratos a serem isolados, as séries a serem instauradas, os critérios de periodização a adotar, considerando que simultaneamente às grandes histórias desenrolam-se outras histórias, outros acontecimentos que não foram monumentalizados.

Algumas questões emergem quando se investigam as bases dos estudos do discurso. Uma primeira que se põe é: Há um gesto inaugural em Foucault quando se trata de estudos do discurso? Quais são os deslocamentos, os cortes, as inovações das proposições de Foucault para a formação basilar dos estudos do discurso? Atua a história como uma condição de possibilidade do discurso? E, enfim qual seria a atualidade do pensamento de Foucault para os estudos do discurso no início do século XXI? Para responder a essas questões, retornaremos aos pontos de encontro entre os estudos do discurso e os conceitos elaborados, em especial, na proposta arqueológica de M. Foucault, na qual se formulam os conceitos de discurso, enunciado, regularidades discursivas, arquivo, vontade de saber, entre outros. 


\section{As ressonâncias de M. Foucault nos estudos do discurso}

A potencialidade de M. Foucault torna-se visível desde suas primeiras incursões no Brasil. Na verdade, antes disso, quando alguns estudiosos brasileiros, provenientes, à época, de uma elite intelectual brasileira, vinculada ao ideal de erudição da tradição francesa, seguem os cursos de Michel Foucault em Paris e, por fruto do reconhecimento do seu trabalho e da admiração pelo filósofo, convidam-no para proferir palestras no Brasil. ${ }^{2}$ Em 1973 ${ }^{3}$, Foucault, convidado pelo Departamento de Letras da PUC do Rio de Janeiro, ao pronunciar as Conferências de Maio de 1973, difunde suas ideias sobre discurso nas aulas do curso que ministrou: A verdade e as Formas Jurídicas.

Entre a publicação de A arqueologia do saber e a vinda de Michel Foucault ao Brasil, houve a publicação da Revista Tempo Brasileiro, RJ, em 1971, sobre a temática $O$ Homem e o Discurso (A arqueologia de Michel Foucault), contendo artigos de Dominique Lecourt, Carlos Henrique de Escobar e Sergio Paulo Rouanet, além de uma entrevista com Michel Foucault, concedida a Rouanet e Merquior. Onipotência e vulnerabilidade do discurso: nisso consiste a centralidade da avaliação dos autores sobre a obra do filósofo. Ainda que a ubiquidade do discurso e sua fragilidade comportem aspectos contraditórios, esses dois fatores são solidários: o mundo contemporâneo está imerso nos discursos. Em 1971, os autores já indicavam a "presença audiovisual do discurso na imprensa falada e escrita; a presença do discurso na propaganda política; a presença do discurso nos textos e imagens publicitárias" (1971] 1996, p.12]), flagrando o discurso dos mass media como um "irresistível veiculador de mitos" (idem). Neste quadro, Foucault "não inventa um mundo sem sujeitos: descreve, realisticamente, um mundo em que o sujeito já foi, ou está sendo, submergido pelo discurso" (idem, p. 13). Entretanto, mesmo diante dessa onipotência, o discurso é vulnerável, seja pela interdição do objeto, seja pela interdição do sujeito que enuncia: não é qualquer discurso que pode emergir e não é qualquer sujeito que pode enunciá-lo. É nesse duplo movimento, no qual estão envolvidos de forma paradoxal e solidária o gesto instaurador e o gesto de segregação, que os discursos vêm a ser descritos e analisados. O parecer dos apresentadores deste número da Revista Tempo Brasileiro mostram a modernidade do pensamento de Foucault, e os caminhos para uma análise dos discursos que enfrente a

\footnotetext{
${ }^{2}$ Roberto Machado (2017), no livro Impressões de Michel Foucault, relata o Seminário no qual lê com seus alunos As palavras e as Coisas, em 1970.

${ }^{3}$ Em outubro de 1965, Foucault fora convidado por G. Lebrun a falar sobre a temática de As Palavras e as Coisas, na Faculdade de Ciências e Letras da USP (MACHADO, 2017).
} 
racionalidade tecnocrática capaz de silenciar o discurso alternativo em favor de um discurso hegemônico, que vem a se implantar de forma única na polis.

Ainda na revista Tempo Brasileiro, sobre a entrevista concedida por Michel Foucault a Sergio Rouanet e J. Merquior, o filósofo considera que A arqueologia do Saber permitiu fazer uma síntese de como foi possível descrever uma História das Ciências - assim como o fez em As Palavras e as Coisas - independentemente de uma história tradicional. Seu esforço n’Arqueologia foi para definir como o analista deve se posicionar para fazer aparecer as razões da existência de uma determinada ciência, do discurso científico articulado a essa ciência e seu funcionamento na sociedade. Com isso, o autor faz uma síntese que vem a dar uma costura aos trabalhos que já fez, assim como anuncia os próximos passos a serem dados. Questionado se após o trabalho de codificação e de sistematização da Arqueologia, pretende voltar à descrição do saber; responde que sim, pretendendo alternar as pesquisas descritivas com as análises teóricas, já que tinha a percepção de que a arqueologia não era nem completamente uma teoria, nem completamente uma metodologia. Assim, Foucault abre os caminhos que virão a ser trilhados nos estudos do discurso.

"[a Arqueologia] Não é uma teoria na medida, por exemplo, em que eu não sistematizei as relações entre as formações discursivas e as formações sociais e econômicas, cuja importância foi estabelecida pelo marxismo de uma forma incontestável. Essas relações foram deixadas na sombra (...). Além disso, deixei de lado, na Archéologie, os problemas puramente metodológicos. Isto é: como trabalhar com esses instrumentos? É possível fazer a análise dessas formações discursivas? A semântica tem alguma utilidade? As análises quantitativas, como as praticadas pelos historiadores, servem para alguma coisa? Podemos então perguntar o que é a Archéologie se não é nem uma teoria, nem um metodologia. Minha resposta é que é alguma coisa como a designação de um objeto: uma tentativa de identificar o nível no qual precisava situar-me para fazer surgir esses objetos que eu tinha manipulado durante muito tempo sem saber se quer que eles existiam, e portanto sem poder nomeá-los" (FOUCAULT, ([1971] 1996, p. 12).

Os conceitos centrais para uma análise arqueológica já estavam, portanto, ali delineados: discurso, práticas discursivas, formação dos objetos, formação das modalidades enunciativas, formação dos conceitos, dos temas e teorias. Em conjunto eles permitem que o analista venha a chegar às regularidades discursivas presentes na formação do discurso. Mas isso não é suficiente. Como ele nos ensina, é necessário o analista posicionar-se para compreender as razões da existência de dado discurso. Para tal, Foucault ocupa-se em definir o enunciado e em problematizar o arquivo e o a priori histórico, contribuições fundamentais para toda a base da Análise do discurso. 
A Ordem do Discurso ainda que seja um texto inaugural e como tal deva responder a essa complexidade de ser um texto que expõe seu caráter de novidade, que supõe um ouvinte que "ainda não sabe", que é ignorante ou ingênuo sobre aquela temática, ele é ao mesmo tempo uma aula que, como afirma Foucault, "implica que se tenha atrás de si todo um conjunto de saberes, de discursos já constituídos" (FOUCAULT, ([1971] 1996, p. 42]). Essa aula, por sua vez, é desencadeadora de uma forma teórico analítica na qual se inscrevem os discursos. De forma inescapável, vê-se que em toda sociedade é tão arriscado dizer, porque "a produção do discurso é ao mesmo tempo controlada, selecionada, organizada e redistribuída" (FOUCAULT, 1996, p. 8-9) por procedimentos externos de controle e de delimitação (a palavra proibida, a segregação da loucura e a vontade de verdade) e procedimentos internos de diminuição do acaso (comentário, autor, sociedade de discurso e disciplina). Além disso, considera ainda as condições de funcionamento a que estão suscetíveis os discursos, seja pela rarefação do sujeito que fala, seja pela apropriação social dos discursos e pelas coerções sociais. Neste quadro, temos, portanto, um conjunto organizado teórico analiticamente sobre como há uma ordem do dizer e como se pode analisar os enunciados efetivamente produzidos que emergem necessariamente no interior desta 'ordem do discurso'.

A proposição analítica de Foucault não é de fato fundada nas dicotomias linguísticas ou nas análises léxico-gramaticais. Não era seu propósito, tampouco seu métier. O movimento inovador de Foucault está no estudo da emergência dos discursos - discursos filosóficocientíficos, por exemplo - nutridos, por sua vez, por uma vontade de verdade. Esse deslocamento da vontade de saber para a vontade de verdade pode ser visto no curso "Aulas sobre a vontade de saber" que se inicia em 09 de dezembro de 1971, dias após a aula inaugural pronunciada no Collège de France. Nesse curso, Foucault volta-se para os estudos dos textos de Aristóteles, a quem reconhecia como o fundador da filosofia, e ainda que cite as análises retóricas daquele período, aponta como os Sofistas 'alimentam' esse deslocamento. A 'vontade de saber' é o título do seu curso, entretanto, seu questionamento maior é como se pode medir o efeito da vontade de verdade nos discursos sobre a história do pensamento; como a vontade de verdade atua como um sistema de exclusão e coerção sobre os discursos e outras práticas - "consiste em saber quais lutas reais e quais relações de dominação são mobilizadas na vontade de verdade" (FOUCAULT, 2014, p. 4). São várias as problematizações que emergem nos jogos das três noções - saber, verdade e conhecimento -, sendo que permeia essa discussão uma pergunta central: se a análise dos saberes, que teria por princípio afastar a presença de um sujeito fundador, vier a ser articulada à vontade de verdade, não estaríamos com isso reinserindo uma sujeito soberano? A resposta a essa questão vem a 
sustentar o movimento articulado entre a arqueologia e a genealogia. A vontade de saber ao deslocar-se para a vontade de verdade não expõe um sujeito, mas, especialmente, os sistemas reais de coerção e dominação. Para Foucault (2014, p. 6), “a verdade - seria melhor dizer o sistema do verdadeiro e do falso - terá revelado o rosto que há tanto tempo vem escondendo de nós, e que é o de sua violência”.

\section{Foucault, o corte epistemológico e seus deslocamentos}

O gesto inaugural de Foucault nos estudos do discurso pode ser perscrutado em várias discussões por ele lideradas. Algumas que atribuem ao discurso o caráter inovador, outras amparadas e produzidas a partir de cortes epistemológicos e ou ainda em deslocamentos. Os textos nos quais Foucault estabelece diálogos e rupturas com a linguística, conforme compreendida no final dos anos de 1960, estão presentes em artigos e livros, por exemplo, n’A Arqueologia do Saber e em um artigo em uma revista tunisiana, denominado Linguística e Ciências Sociais (1969), derivado do debate havido na Universidade da Tunísia em março de 1968.

No artigo Linguística e Ciências Sociais, cuja discussão focaliza os problemas que a Linguística introduz no pensamento geral das Ciências Humanas, Foucault pondera que a análise da linguagem atribuída a Saussure e divulgada por seus sucessores atingiu, no século $\mathrm{XX}$, o que se poderia chamar de 'limiar de cientificidade'. Isso se deu graças às técnicas de formalização da linguística e à expressão da ideia de que a linguística atingiu um nível de formalização superior que iluminaria as outras áreas, sejam mais próximas - como a Teoria da comunicação e da informação -, sejam mais distantes como as Ciências da natureza. Avaliase, entretanto, que a relação das ciências da linguagem com outras ciências tem uma história antiga, estabelecida às vezes por transposição de domínios - o modelo estrutural servindo à análise dos mitos, das relações de parentesco -, e às vezes por relações de causalidade racionalização feita pelo domínio empírico estabelecido pela relação de causalidade entre um fenômeno e outro. Foucault aponta como a linguística insere nesta discussão outro instrumento de racionalização do real, que vem a ser as relações lógicas, que não são necessariamente da ordem da causalidade. Sobre essa questão, creio ser propício remeter à própria expressão de Foucault: 
Creio que esse problema da presença de uma lógica que não é a lógica da determinação causal está atualmente no âmago dos debates filosóficos e teóricos. A retomada, a reativação, a transformação dos temas marxistas no pensamento contemporâneo giram em torno disto: assim, o retorno a Marx ou as pesquisas sobre Marx do tipo althusseriano mostram que a análise marxista não está ligada a uma atribuição de causalidade: elas tentam libertar o marxismo de uma espécie de positivismo [...]. O que se tenta reencontrar em Marx é alguma coisa que não seja nem a atribuição determinista da causalidade, nem a lógica do tipo hegeliano, mas uma análise lógica do real (FOUCAULT, 2005, p. 163-164).

Pautada nessa manifestação de Foucault, julgo termos uma primeira percepção do deslocamento dos estudos linguísticos em direção a outras frentes, opondo-se às teorias idealistas e às lógicas retóricas. Nessa visada, os estudos filosóficos franceses sobre a linguagem nos anos 1960 e 1970 recusaram também a aproximação da Linguística com a teoria da comunicação que reafirmava uma definição de língua como forma de comunicação na qual se compreendem "polos emissores, de um lado, e receptores, de outro; mensagens, ou seja, séries de acontecimentos distintos; códigos ou regras de construção dessas mensagens que permitem individualizá-las" (idem, p. 164). Essa perspectiva é questionada por Foucault que vê nisso a produção de um afastamento da história: para ele, o ponto de vista sincrônico não é a-histórico (que seria o presente contra o passado), nem anti-histórico (o imóvel contra o evolutivo). A sincronia numa perspectiva estrutural comportaria, ao seu olhar, o sucessivo e o simultâneo. Além disso, não seria também o corte estático que viria a negar a evolução, pois continua sendo parte dessa constituição a "análise das condições nas quais uma evolução pode se dar" (idem, p, 165). Essas reflexões incorporam, assim, a mudança no interior da análise sincrônica e afastam a causalidade como tema orientador da análise. Essa concepção de mudança trazida para o interior das disciplinas introduzem as noções de descontinuidades e de transformações ${ }^{4}$.

Com essa nova visada da linguística que envolveu as condições de possibilidade de descrição da linguagem, "a linguística permitiu, enfim, analisar não somente a linguagem, mas os discursos [...] fez aparecer as condições de mudança graças às quais se podem analisar os fenômenos históricos, enfim, realizar a análise do que se poderia chamar de produções discursivas" (idem, p. 167). Estão, então, delineados os primeiros gestos de aproximação entre os assentados preceitos da linguística e a unidade de discurso como referência de estudo.

\footnotetext{
${ }^{4}$ Remeto ao artigo de M. Foucault, denominado "Resposta a uma questão", publicado originalmente na Revista Spritt, n. 371, em maio de 1968. p. 850-874 (Publicação brasileira em Ditos e Escritos VI - Repensar a política. Rio de Janeiro: Forense Universitária, 2010), no qual o autor explica a razão por manter esses dois termos no plural.
} 
Ainda em um gesto que anuncia reflexões inaugurais, Foucault vê no método arqueológico (FOUCAULT, [1969] 1986) o modo de encontrar e analisar as regularidades discursivas. E em que aspecto emerge seu caráter inovador? Ele irá investigar as regularidades na dispersão. Ao mesmo tempo em que recusa o Zeitgeist (espírito da época) e a História das Mentalidades, traz à tona o conceito de descontinuidade, que metodologicamente é seu ponto de partida. Foucault, em seu método de análise histórica isento de qualquer antropologismo, propõe libertar-se do tema da continuidade, afastando, neste gesto de ruptura, as unidades da tradição (atribuição indefinida à origem), da influência (atribuição de um processo causal aos fenômenos de semelhança ou repetição), da evolução (atribuição a um princípio de coerência o esboço de uma unidade futura) e da mentalidade (atribuição da consciência coletiva a uma soberania).

A análise das regularidades discursivas ampara-se em sistemas de formação: formação dos objetos, dos modos de enunciação, dos conceitos e dos temas e teorias. As regras de formações discursivas existentes em meio à dispersão podem ser definidas por meio da análise do objeto: os discursos são práticas que formam os objetos, formalizando, assim, a observação de que os objetos não preexistem ao discurso, eles são construídos pelos discursos. Esse modo de fazer análise envolve a problemática de como recortar as formações discursivas, que são sistemas de dispersão. Para tal mobiliza-se o conceito de enunciado: diferentes em suas formas, dispersos no tempo, os enunciados podem formar um conjunto quando se referem a um único e mesmo objeto, instaurando assim um discurso. Atentemonos, entretanto, que se trata de um discurso que se forma em meio à dispersão e, portanto, é suscetível a transformar o objeto. O objeto loucura estudado por Foucault é um exemplo de como não há uma homogeneidade no discurso sobre o objeto.

As regras da modalidade enunciativa, se por uma hipótese abrigariam um determinado estilo no enunciado, por exemplo, um mesmo modo de se enunciar o discurso médico sobre a loucura, por outra hipótese essas regras levam-nos a considerar que há diferentes práticas discursivas que, por meio de distintas modalidades enunciativas, expõem diversas posições daqueles que enunciam em diferentes lugares que ocupam.

Sobre o sistema de formação dos conceitos, se consideramos o sistema de dispersão, não temos, portanto, em um grupo de enunciados, a formação de conceitos permanentes e coerentes, mas conceitos que devem ser analisados no jogo de seus aparecimentos e dispersões, uma vez que os conceitos se organizam no campo do discurso e não preexistem a esse campo. Aliás, essa é uma das distinções centrais a respeito do qual Foucault mostra como sua análise envolve uma mudança de terreno. Tomando como exemplo os dois modos como a 
tradição faz a descrição das plantas e dos animais, Foucault (1986) explica o conceito de discurso. Em uma análise baseada na unidade do sistema de pensamento haveria apenas dois modos de descrever as plantas e animais. 1) Parte-se das plantas e animais para se dizer sendo eles aquilo que são, como as pessoas de determinado século os viram e os descreveram. O que observaram. O que omitiram. Ou ainda 2) ao se recensear as palavras e os conceitos que em determinada época se dispõe, como poderá vir a se definir as plantas e os animais? Foucault propõe, baseado no sistema das regras de formação discursiva que implica o sistema de dispersão, analisar o discurso que explica o porquê de tal objeto ser visto ou omitido, ser expresso por determinada modalidade enunciativa, responder ou não a conceitos já existentes, sustentar-se em dada teoria para justificar sua formação estratégica (temas e teorias).

O corte epistemológico de Foucault opera metodologicamente ao opor a noção de unidade à de descontinuidade, o sujeito antropológico ao sujeito histórico, a análise do pensamento à análise do campo discursivo, a análise dos processos causais à análise enunciativa que compreende a coexistência de enunciados dispersos e heterogêneos. Efetua, enfim, o deslocamento da análise de um sistema de pensamento para a análise do estudo arqueológico de descrição dos acontecimentos discursivos. Também em relação à análise linguística, Foucault traça recortes e limites. Enquanto a análise da língua, nas décadas de 1960 e 1970, se estabelece por quadro de diferenças - estruturais ou de caráter gerativista (segundo que regras um enunciado foi construído, e, consequentemente, segundo quais regras outros enunciados semelhantes poderiam ser construídos), - Foucault estabelece a análise dos enunciados por sistemas de dispersão: sendo o campo de descrição dos acontecimentos discursivos um conjunto definido de discursos, o analista se pergunta: "como apareceu um determinado enunciado, e não outro em seu lugar?” (FOUCAULT, 1986, p. 31).

\section{A história como uma condição de possibilidade do discurso}

Se há inovações em Foucault para os estudos do discurso, apontamos que elas se mostram de forma fundamental em sua concepção de sujeito e em seu questionamento sobre os modos de composição e análise do arquivo. Comentadores da obra do filósofo indicam também sua inovação quanto à existência de uma Analítica interpretativa ${ }^{5}$, que viria a nuclear seus estudos, ainda que o seu desejo de marginalidade e desafio às estabilidades disciplinares

\footnotetext{
${ }^{5}$ Conforme Dreyfus e Rabinow (1995).
} 
estivesse sempre presente em seus estudos. O autor sempre parece preferir o lugar marginal, busca escapar à ordem do discurso. Dizer que ele defenda a criação de uma nova disciplina com suas teorias e métodos seria contrariá-lo em sua essência.

Esses gestos analíticos, no entanto, é que deram fôlego à proposição de novos recortes arquivistas, ao questionamento da estabilidade das obras, das noções de criação e originalidade, da centralidade da significação dada previamente. Em A Arqueologia do saber, Foucault propõe regras do método de análise, que levam a 4 noções de princípio regulador - o acontecimento (em oposição à criação), a série (em oposição à unidade), a regularidade (em oposição à originalidade) e as condições de possibilidade (em oposição à soberania do significante, reconhecendo que o discurso é uma violência que se faz às coisas).

No texto denominado "Resposta a uma questão" (FOUCAULT, 2010), Foucault dispõe-se a responder uma das diversas questões que lhe foram postas, avaliando a centralidade do que lhe foi perguntado: "Um pensamento que introduza coerção do sistema e a descontinuidade na história do espírito não tira ele todo fundamento de uma intervenção política progressista?” A resposta do filósofo de início refere-se a expor o caráter pluralista de sua proposta teórica. Sistemas e descontinuidades no plural. Ele não objetiva com suas análises chegar ao pensamento de uma época, revelar a grande história, mas “os tipos de história - quer dizer de remanência e transformação - que caracterizam os diferentes discursos" (FOUCAULT, 2010, p. 4). Analisando, portanto, o conjunto de discurso em suas transformações, limiares e remanências, chega-se ao seu feixe de relações, sendo a história a condição de possibilidade da emergência de discursos. Da mesma forma, dá-se a relação com as descontinuidades - no plural - uma vez que a história é onde se pode flagrar a análise descritiva e a teoria das transformações que estão suscetíveis aos movimentos, entretanto, não se trata de uma história imóvel, tampouco a história em sua descontinuidade esperaria o preenchimento de seus autores de um suposto vazio entre os acontecimentos. O que a arqueologia propõe é a descrição do arquivo e não a formalização de um sistema ou as relações causais entre acontecimentos. A análise arqueológica busca definir os próprios discursos, enquanto práticas discursivas e, portanto, para isso não acessa o arquivo como um documento, sem questionar os materiais arquivados, sem alertar-se para o fato de que eles não são transparentes. Diferentemente, o arquivo é acessado como um monumento, a respeito do qual se deixa ver a historicidade, permite analisar as relações que regem a aparição dos enunciados em seu volume próprio onde se pode apreender a história das coisas ditas em sua formação e transformação. 
Resta, entretanto, explicar como a história é ainda condição de possibilidade do discurso na forma de expressão de suas práticas políticas. Uma política progressista amparase, de fato, no avesso às totalidades, no questionamento das unidades estáveis e suas supostas transparências, na problematização da história global. Um modelo arqueológico apoia-se na valorização das práticas discursivas, na concepção de um sujeito historicamente constituído, na análise de emergência, funcionamento e transformações de enunciados que atuam inevitavelmente em uma prática política que se articula a outras práticas. Enfim, em resposta à questão que lhe foi posta ${ }^{6}$, Foucault expõe como os sistemas, as descontinuidades e as práticas políticas articulam-se com os discursos em seus limites e formas de dizibilidade (o que é possível falar), de conservação (quais enunciados são destinados a serem mantidos ou esquecidos), de memória (quais enunciados devem ser validados ou abandonados), de reativação (quais enunciados devem ser retidos, transformados e quais discursos retornam) e de apropriação (quais sujeitos têm acesso a quais tipos de discurso nesta luta de domínio de discursos). Uma reflexão que decodifica e problematiza a existência das formas e dos limites de formulação e distribuição dos discursos alinha-se a práticas políticas progressistas, conforme expõe Foucault (2010, p. 22): “uma política progressista é uma política que reconhece as condições históricas e as regras específicas de uma prática, [...] que define, em uma prática, as possibilidades de transformação" e que vê a articulação entre as práticas discursivas.

\section{A arquegenealogia continua a iluminar as análises do século XXI?}

“Sou um diagnosticador do presente!" era a forma como, segundo Artières (2004), M. Foucault gostava de caracterizar sua atuação nos trabalhos sobre os quais se dedicava. Publicou livros, ministrou cursos que posteriormente vieram a ser publicados e, afastando-se das formas tradicionais de divulgação do pensamento intelectual, concedeu muitas entrevistas, escreveu a muitos jornais, atuou em movimentos (como o GIP), fazendo do seu próprio corpo o discurso de resistência. A atualidade do seu pensamento não é advinda, entretanto, da aplicação direta de um modelo teórico-analítico, ela vem, sobretudo, da possibilidade de iluminar os modos de pensar, de questionar, de analisar os fatos contemporâneos. Foucault

\footnotetext{
${ }^{6}$ Conforme o artigo "Resposta a uma questão", no qual Foucault dispõe-se a responder a seguinte questão: "Um pensamento que introduz a coerção do sistema e a descontinuidade na história do espírito não tira ele todo fundamento de uma intervenção política progressista?"
} 
oferece, aos estudos do discurso, uma lente capaz de nos auxiliar a tornar visível o que é visível. Como ele mesmo afirma, trata-se de "fazer aparecer o que está tão perto, o que é tão imediato, o que está tão intimamente ligado a nós mesmos que exatamente por isso não percebemos" (FOUCAULT, 2001, apud GROS, 2004, p. $15^{7}$ ). De uma perspectiva do discurso, incita a buscar os sentidos nos enunciados efetivamente enunciados e não supostamente escondidos ou subjacentes.

Em seu estudo arqueológico, Foucault já anuncia que o estudo do discurso se dispõe em dois conjuntos: o crítico (princípio da inversão) e o genealógico (princípios da descontinuidade, especificidade, exterioridade). Consecutivamente, a perspectiva arquegenealógica, que articula os estudos do arquivo às relações de poder, tem valor propedêutico em seus estudos da década de 1970, seja em Aulas sobre a vontade de saber (curso de 1970-1971), seja em A sociedade punitiva (curso de 1972-1973). No primeiro, Foucault (2014) mostra que a relação entre o saber, a verdade e o conhecimento estão implicadas de forma incontornável. Já havia nesse curso (e mesmo na aula inaugural do Collège de France) um anúncio da genealogia do saber, caminho pelo qual seria possível mostrar que as condições de emergência dos enunciados e os limites de sua enunciabilidade são definidos não pela língua ou pelo conhecimento, mas por uma vontade de saber que não se separa de uma vontade de verdade inevitavelmente dependente das relações de poder.

No segundo curso - A Sociedade Punitiva -, Foucault (2015), ao estudar as formas de punição, apresenta a análise da passagem de uma sociedade monárquica para uma sociedade burguesa que deve controlar a produtividade e expõe como se edificam neste momento as relações moleculares de poder. O filósofo estabelece com isso um outro ponto de vista sobre os estudos que centralizavam as relações de poder exclusivamente nas lutas de classe. Ele flagra - nesta análise dos saberes - as lutas, os conflitos, as decisões táticas que sustentam as práticas de saber-poder no interior das relações sociais, não em um jogo de identidades (saber é poder), mas de uma forma específica que obedece a um jogo complexo.

$\mathrm{O}$ avanço dos estudos das formas históricas de poder e suas relações com o sujeito (FOUCAULT, 1995) se tornaram centrais nas pesquisas de Foucault no final dos anos de 1970 e início dos anos de 1980. O poder pastoral, a sociedade disciplinar e o biopoder, como formas de funcionamento do poder na sociedade contemporânea, dialogam com o poder dos arquivos e com a vontade de verdade. Estes elementos em conjunto atuam de forma continuada nas condições de emergência dos discursos e nas formas e limites da

\footnotetext{
${ }^{7}$ Foucault, M. Dits e écrits II, Paris: Galimard, 2001, p. 540-541.
} 
enunciabilidade dos enunciados. O século XXI, neste início, caracteriza-se pela luta de apoio aos discursos que comportem o direito à diferença, o afastamento dos discursos autoritários e $\mathrm{o}$ respeito à pluralidade de pensamentos. E, ao mesmo tempo, questiona o crescimento das formas biopolíticas de controle social que intimidam e excluem parte da sociedade.

Ancoramentos sócio-históricos são feitos com base em relações de poder. $\mathrm{O}$ giro à direita no Brasil, no ano de 2018 na política governamental, expõe o conflito entre as leituras dos acontecimentos, valendo-se da construção de vontades de verdade que se sustentam pela hierarquia da legitimidade, que se edificam e sustentam-se por discursos de imposição religiosa, moral e política. Há uma luta que se dá pelo confronto de discursos e essa luta move a resistência. Em meio a isso, Foucault continua a nos iluminar:

O que tenho estudado são três problemas tradicionais: 1) Quais são as relações que temos com a verdade por meio do saber científico, quais são nossas relações com esses "jogos de verdade" que são tão importantes na civilização e nos quais somos, ao mesmo tempo, sujeito e objeto? 2) Quais são as relações que estabelecemos com os outros por meio dessas estranhas estratégias e relações de poder? Por fim, 3) Quais são as relações entre verdade, poder e si? (FOUCAULT, 2004).

As questões tão atuais levantadas por Foucault indicam a permanência da inscrição dos discursos em relações de saber-poder, a pertinência de se questionar os recortes arquivistas, a centralidade das noções de saber, conhecimento e verdade a serem sempre objeto de análise. Sim, a nosso ver, Foucault tem um gesto inaugural na formação dos estudos do discurso, um gesto que não se conclui com a arqueologia ou mesmo com a arquegenealogia; somam-se às questões sobre a verdade, o saber e o poder, a problematização da ética, numa perspectiva, não da individualidade, mas que toca a sociedade quanto questionar a sua forma de seguir cegamente, de obedecer de forma irrefletida, de submeter-se ao governo do outro (GROS, 2018). Em sua coerência, Foucault, ao longo de suas publicações e cursos, sempre soube do poder dos discursos e legou-nos a tarefa de resistir com eles.

\section{Referências}

ARTIÈRES, P. Dizer a atualidade. O trabalho de diagnóstico em Michel Foucault. In. GROS, F. (org.). Foucault, a coragem da verdade. Tradução de Marcos Marcionilo. São Paulo: Parábola Editorial, 2004. 
FOUCAULT, M. A ordem do discurso. Tradução de Laura Fraga de Almeida Sampaio. São Paulo: Ed. Loyola, 1996.

FOUCAUlT, M. A arqueologia do Saber. 2 ed. Tradução de Luiz Felipe Baeta Neves. Rio de Janeiro: Forense Universitária, 1986.

FOUCAULT, M. O sujeito e o poder. In. RABINOW, P.; DREYFUS, P. Michel Foucault, uma trajetória filosófica: para além do estruturalismo e da hermenêutica. Tradução de Vera Porto Carrero. Rio de Janeiro: Forense Universitária, 1995, p. 231-249.

FOUCAUlT, M. Verdade, Poder e si. In: FOUCAULT, M. Por uma vida não-fascista. Coletivo Sabotagem, 2004, p. 51-56.

FOUCAULT, M. Linguística e Ciências Sociais. In. FOUCAULT, M. Ditos e Escritos II Arqueologia das ciências e a história dos sistemas de pensamento. Organização e seleção de textos, Manoel Barros da Motta, tradução de Elisa Monteiro. 2 ed. Rio de Janeiro: Forense Universitária, 2005, p. 163-181.

FOUCAULT, M. Resposta a uma questão. In. FOUCAULT, M. Ditos e Escritos VI Repensar a política. Organização e seleção de textos, Manoel Barros da Motta, tradução de Ana Lúcia Paranhos Pessoa. Rio de Janeiro: Forense Universitária, 2010, p. 1-24.

FOUCAULT, M. Aulas sobre a vontade de saber: curso no Collège de France (1970-1971) / Michel Foucault; seguido de O saber de Édipo. Tradução de Rosemary Costhek Abílio. São Paulo: Editora WMF, Martins Fontes, 2014.

GROS, F. Foucault: a coragem da verdade. Tradução de Marcos Marcionilo. São Paulo: Parábola Editorial, 2004.

GROS, F. Desobedecer. Tradução de Célia Euvaldo. São Paulo: Ubu Editora, 2018.

MACHADO, R. Impressões de Michel Foucault. São Paulo: N-1 edições, 2017. 240 p.

RABINOW, P; DREYFUS, H. Uma trajetória filosófica. Para além do estruturalismo e da hermenêutica. Tradução de Vera Porto Carrero. Rio de Janeiro: Forense Universitária, 1995.

ROUANET, S.; MERQUIOR, J. Entrevista com Michel Foucault, Revista Tempo Brasileiro. Comunicação / 3 - O homem e o discurso. 2 ed. Rio de Janeiro: Edições Tempo Brasileiro, 1996.

Recebido em: 6 de maio de 2019

Aceito em: 21 de junho de 2019 